\title{
Na pandemia da Covid-19, o Brasil enxerga o SUS
}

Ana Maria Costa1,2, Maria Lucia Frizon Rizzotto1,3, Lenaura de Vasconcelos Costa Lobato ${ }^{\mathbf{1}, 4}$

DOI: 10.1590/0103-1104202012500

NO MOMENTO QUE ESCREVEMOS ESTE EDITORIAL, somam-se 122 dias do registro do primeiro caso da Covid-19 no Brasil, confirmado em São Paulo, no dia 25 de fevereiro de 20201. A pandemia encontrou a Nação com um governo de ultradireita, militarizado, desnorteado e submerso em uma crise política, agravada por um baixo desempenho da economia com crescimento do Produto Interno Bruto (PIB), em 2019, de apenas 1,1\% e contabilizando cerca de 13 milhões de desempregados. Essa combinação de fatores e crises tem aprofundado a instabilidade política e se revelado trágica sob todos os pontos de vista, fazendo com que o País se assemelhe a uma nau sem rumo, prestes ao naufrágio.

Temos, hoje, 928.985 casos confirmados de infectados pelo Sars-CoV-2, embora as estimativas alertem para números, pelo menos, 8 a 10 vezes mais elevados em virtude da baixa testagem praticada em nosso território. Em ritmo de crescimento acelerado, são registrados mais de 20 mil novos casos diagnosticados diariamente, acumulando, lamentavelmente, 53.895 mortes, sendo 1.185 nas últimas 24 horas $^{2}$. Com esses dados, o Brasil passa a ser o segundo país em número de mortes, ultrapassado, no momento, apenas pelos Estados Unidos.

A pandemia atingiu em cheio o narcisismo da sociedade, sempre alimentado pela satisfação com a negação da realidade. Escancara-se a abissal desigualdade social agora tão escandalosamente exposta quanto antes fora negada. O Brasil que emergirá desta crise sanitária já não poderá esconder de si a imagem que revelou seus milhões de pobres e miseráveis desprovidos de condições mínimas para o cumprimento das normas sanitárias preconizadas para o controle da pandemia: ficar em casa, manter distanciamento social, lavar as mãos e se alimentar adequadamente. Esse espelho, se não for de novo quebrado - e a incômoda imagem, esquecida outra vez -, exigirá mudanças radicais no modelo de desenvolvimento e na política econômica. As transformações envolvem admitir que um País mais justo e menos desigual apenas é possível por meio da adoção de uma política econômica não ortodoxa que institucionalize mecanismos universais de proteção social, garantindo uma renda básica de cidadania e promovendo um efetivo aumento do investimento público para ampliar o mercado de trabalho e absorver os brasileiros hoje abandonados ${ }^{3}$.

O auxílio emergencial de R $\$ 600,00$, aprovado pelo Congresso Nacional, em lugar dos R\$ 200,00 propostos pelo governo federal, já foi solicitado por $43 \%$ da população brasileira; e, destes, apenas $60 \%$ receberam ao menos uma parcela do dinheiro ${ }^{4}$.

O resultado está na 'desobediência' às recomendações sanitárias, refletida nas baixíssimas taxas de isolamento encontradas nas grandes metrópoles e estados brasileiros que, mesmo em

\footnotetext{
1 Centro Brasileiro de Estudos de Saúde (Cebes) - Rio de Janeiro (RJ), Brasil. dotorana@gmail.com

2 Escola Superior de Ciências da Saúde (ESCS)

- Brasília (DF), Brasil.

3 Universidade Estadual do Oeste do Paraná (Unioeste) - Cascavel (PR), Brasil

4 Universidade Federal Fluminense (UFF) - Niterói (RJ), Brasil.
} 
situação de lockdown, não conseguem atingir o nível desejável de distanciamento social. Sem o apoio do auxilio emergencial ou outra forma de garantir renda, os trabalhadores precários não podem deixar de trabalhar e usar os transportes públicos abarrotados que continuam circulando nas grandes cidades. É essa mesma população acostumada ao tráfico e às milícias que convive com a violência policial, crescente em tempos de evidente instalação do autoritarismo no País 5 .

As dificuldades com o pagamento do auxílio, registradas nas milhares de respostas 'em análise' do aplicativo da Caixa Econômica Federal e nas imensas filas nas portas das agências, não são apenas problemas de gestão. Caso quisesse agilizar os pagamentos e a identificação dos brasileiros com direito efetivo ao auxílio, o governo teria usado a estrutura do Sistema Único de Assistência Social (Suas) e ampliado a rede bancária para efetivar o pagamento. Ao contrário, o auxílio foi centralizado na Caixa Econômica Federal e administrado pelo Ministério da Economia, sem participação do Ministério da Cidadania, que tem (ou tinha) o aparato técnico e tecnológico para lidar com programas sociais. O que faltou foi comprometimento que mobilizasse o conhecimento e a habilidade para lidar com os problemas do povo, já que o projeto econômico do governo se baseia exclusivamente em cortar gastos e privatizar.

A lógica antiproteção social foi ainda mais grave na ação deliberada de desmonte do Ministério da Saúde, com demissão de quadros técnicos e troca de três ministros desde o início da pandemia, agora dirigido por um militar disciplinado e obediente mais aos anseios políticos do governo do que às necessidades de saúde da população, que desconhece a geografia do próprio País e nada sabe de saúde e do Sistema Único de Saúde (SUS).

Outra situação de enorme gravidade é a ausência de liderança que conduza o Brasil no enfrentamento da pandemia, uma vez que o próprio presidente opta por gerar crises políticas com os Poderes da República, em que adota posição negacionista, minimizando a gravidade da doença e a extensão da pandemia, orientando a população em sentido contrário ao indicado pela ciência, por organismos nacionais e internacionais de saúde e pela experiência acumulada por outros países. Essa omissão do papel de líder da Nação inegavelmente contribui para a ampliação e para o agravamento da tragédia sanitária, seja pela ambiguidade na comunicação, seja pela mentirosa indicação de fármacos sem eficácia comprovada. A recusa do governo federal em conduzir de forma responsável as ações de controle e mitigação do sofrimento do povo durante a pandemia fez com que governadores e prefeitos, em consonância com o interesse público, passassem a assumir o processo, mesmo que sob forte e constante ataque do presidente e sem a coordenação nacional do Ministério da Saúde.

Esse profundo desamparo do povo brasileiro descortina o valor e a importância do SUS que, apesar de suas fragilidades históricas, agiganta-se diante do desafio e, com todo sacrifício, enfrenta a pandemia. As insuficiências e as dificuldades, que já eram visíveis pelo subfinanciamento crônico do Sistema, foram brutalmente agravadas pela Emenda do Teto dos Gastos (EC-95), que congela por 20 anos o investimento em políticas sociais. Segundo o Conselho Nacional de Saúde, o SUS perdeu, somente em 2019, R\$ 20 bilhões com a EC 95. Lutando contra condições precárias para salvar vidas, milhares de profissionais de saúde se infectam e adoecem por falta de equipamentos de proteção individual, colocando o Brasil entre os países que mais perderam profissionais de saúde para a morte.

A Comissão de Financiamento da Saúde, órgão de assessoramento do Conselho Nacional de Saúde, vem produzindo informes semanais para monitoramento da execução e do gasto dos recursos destinados ao combate à pandemia no País ${ }^{6}$. Os dados mostram que, enquanto os casos e as mortes provocadas pela Covid-19 crescem exponencialmente, o Ministério da Saúde fica semanas seguidas sem gastar a maior parte do orçamento destinado à pandemia. Segundo o último Boletim Cofin/CNS (com dados até 8 de junho), o valor a empenhar totalizou R $\$ 26$ 
bilhões dos R $\$ 39$ bilhões disponíveis, ou seja, 67\% dos recursos estão parados ${ }^{6}$. Estão sem uso 76\% dos recursos de Aplicação Direta do Ministério da Saúde, 60\% de Transferência para Estados e 66\% de Transferência para Municípios. Em comparação aos valores das dotações autorizadas para cada uma dessas modalidades de aplicação, os valores pagos representaram, respectivamente, $10 \%, 39 \%$ e $34 \%$ do total destinado .

Essa situação seria considerada um escândalo em qualquer país civilizado, pois, em meio a uma pandemia, com os casos e mortes crescendo exponencialmente há 16 semanas, o Ministério da Saúde mantém $67 \%$ de recursos parados no orçamento, sem sequer serem empenhados. Não é somente incompetência, é ação deliberada para não gastar, deixando o SUS e o povo brasileiro à própria sorte. Ao contrário da lerdeza na aplicação dos recursos tão necessários ao SUS neste momento, vê-se a velocidade com que, em nome do esforço de 'guerra' contra a pandemia, o governo 'protegeu' o sistema bancário permitindo a compra de títulos podres dos bancos, cujo prejuízo aos cofres públicos pode chegar a vários trilhões de reais. Também é bom não esquecer da tentativa do governo, abortada prontamente pela forte crítica da sociedade e do Congresso Nacional, de transferência de R \$ 83,9 milhões do Bolsa Família para a Secretaria de Comunicação.

Ao mesmo tempo que acompanha atônita o descaso e a desorientação do governo, a sociedade enxerga e se surpreende com a presença diária do sistema público nos noticiários, de forma nunca apresentada antes, salvando muitos brasileiros, e sofrendo a perda de tantos de nós. É um sentimento de reconhecimento do SUS e de seu valor como bem público. Curiosamente, o sistema privado saiu de cena nestes tempos de pandemia embora beneficiado pela falta de uso dos serviços rotineiros por seus usuários acuados pelo surto, mas que mantém em dia suas mensalidades. O acesso universal do SUS entre nós contrasta com o que vemos na experiência americana, em que, sem sistema público, muitos cidadãos com sintomas da Covid-19 fogem do tratamento, morrem em casa, nas ruas e parques por medo da conta que não podem pagar. Aqui, mesmo a duras penas, o SUS atende todos os brasileiros que dele dependem, sem nenhum custo. É um direito de todos.

É cedo para previsões e prognósticos sobre o futuro, mas esse novo status da importância do SUS bem poderia representar a força e a pressão política para a consolidação do sistema que foi criado para garantir o direito universal à saúde e que vem encontrando tantas pedras no seu caminho. A maior delas, já que dela decorre soluções para tantas mazelas, é garantir financiamento adequado, revogando o teto dos gastos e definindo um volume justo e adequado de financiamento ao seu revigoramento e consolidação.

Este é o momento para ampliar a consciência crítica que confere valor social sobre o direito à saúde e a defesa do SUS como basilar à democracia. Nessa direção, o Centro Brasileiro de Estudos de Saúde (Cebes) tem realizado ações com os movimentos sociais e com a própria sociedade, com destaque para duas campanhas recentes que resultaram na mobilização de uma diversidade de atores sociais, a campanha \#emdefesadoSUS e a Marcha pela Vida. Celebramos e saudamos também os jovens das periferias que lideram e mobilizam manifestações contra o racismo e por democracia, em defesa da vida.

O Cebes investe-se na sua responsabilidade como ator político em defesa da vida e do direito à saúde e em defesa do SUS, e reafirma sua consigna: 'Saúde é democracia, democracia é saúde!'.

\section{Colaboradoras}

Costa AM (0000-0002-1931-3969)*, Rizzotto MLF (0000-0003-3152-1362)* e Lobato LVC (0000-0002-2646-9523)* contribuíram igualmente para a elaboração do manuscrito.
${ }^{*}$ Orcid (Open Researcher and Contributor ID). 


\section{Referências}

1. Brasil. Ministério da Saúde. Sistema Nacional de Agravos de Notificação Compulsória. [acesso em 2020 jun 16]. Disponível em: https://portalsinan. saude.gov.br/calendario-epidemiologico-2020.

2. Fundação Oswaldo Cruz. Instituto de Comunicação e Informação Científica e Tecnológica em Saúde. Monitora COVID. [acesso em 2020 jun 17]. Disponível em: https://bigdata-covid19.icict.fiocruz.br/.

3. Fleury S. Golpe na Saúde. [acesso em 2020 jun 16]. Disponível em: https://outraspalavras.net/ crise-brasileira/o-golpe-na-saude/.

4. O Globo. G1. Dados do Datafolha. [acesso em 2020 jun 16]. Disponível em: https://gl.globo.com/ economia/noticia/2020/05/28/auxilio-emergencial-13-de-quem-requisitou-beneficio-nao-recebeu-nenhuma-parcela.ghtml.

5. Abramo HW. Jovens da periferia no centro da cena política. [acesso em 2020 jun 16]. Disponível em: https://teoriaedebate.org.br/2020/06/12/jovens -da-periferia-no-centro-da-cena-politica/.

6. Brasil. Conselho Nacional de Saúde. Boletim COFIN. [acesso em 2020 jun 16]. Disponível em: http://conselho.saude.gov.br/images/comissoes/cofin/boletim/Boletim_2020_0609_T1_2Ae2B_3_4_ate_08_ RB-FF-CO_rev.pdf. 